\title{
The Vibration Quantitation Scale (VQS): A Simple, Reproducible Bedside Measure of Sensory Function in Multiple Sclerosis
}

\author{
J. Carter, T. Wasser, S. Statler, A.D. Rae-Grant
}

\begin{abstract}
Objectives: To assess the utility of a bedside measure of sensation (the Vibration Quantitation Scale (VQS)) in patients with multiple sclerosis (MS) and in normal controls. To correlate the VQS with the Kurtzke Expanded Disability Severity Score (EDSS) and sensory abnormalities in these patients. Methods: We developed the VQS and tested its performance in patients with MS of various ages, MS types, and EDSS scores. We compared this with controls (normal volunteers or patients with other neurological diseases) who did not have sensory symptoms. In a subgroup, two examiners measured VQS independently at the same patient visit. Astandard C-128 tuning fork was used for the VQS measurement. Results: The VQS had a good inter-observer reproducibility $(\mathrm{r}=0.920$, $\mathrm{p}<0.001)$. The VQS fell with increasing age in normals consistent with declining sensory function. The VQS was significantly lower in the multiple sclerosis patients compared with age - matched controls ( $\mathrm{p}<0.001)$. Abnormalities in VQS were present in patients with brief duration of MS $(<5$ years) and low EDSS scores, correlating with the presence of sensory abnormalities early in the disease course in some patients. There was a strong correlation between the VQS and EDSS ( $\mathrm{r}=-0.509)$. The VQS correlated with abnormal sensation in the hands ( $\mathrm{r}=0.310)$, but did not meet statistical significance for abnormal sensation in the feet or face. Asecond cohort of MS patients was studied using a modified VQS measure (single stimulation, omitting forehead measurement). This reconfirmed the correlation between the modified VQS and EDSS as well as with age. The modified VQS may be useful in clinical practice since it takes little time and is strongly correlated with the EDSS $(\mathrm{r}=0.578)$. Conclusions: The VQS provides a continuous sensory scale applicable in most patients with MS, which is measurable with standard bedside equipment, and which may avoid some of the pitfalls of sensory scoring in MS.
\end{abstract}

RÉSUMÉ: L'échelle de quantification des vibrations, une mesure simple et reproduisible de la fonction sensitive au chevet du patient atteint de sclérose en plaques. Objectifs : Évaluer l'utilité d'une mesure de la fonction sensitive par l'échelle de quantification des vibrations (ÉQV) au chevet du patient chez des patients atteints de sclérose en plaques (SEP) et des témoins normaux et d'établir des corrélations entre l'ÉQVet l'échelle de Kurtzke, Expanded Disability Severity Score (EDSS), et les anomalies sensitives chez ces patients. Méthodes : Nous avons développé l'ÉQVet évalué son utilité chez des patients de tout âge, atteints de différentes formes de SEPet ayant des scores varies à l'EDSS . Nous avons comparé ces données avec celles de sujets témoins, soit des volontaires normaux ou des patients atteints d'autres maladies neurologiques qui n'avaient pas de symptômes sensitifs. Chez un sous-groupe de patients, deux examinateurs ont évalué l'ÉQV indépendamment l'un de l'autre à la même visite du patient. Un diapason standard C-128 a été utilisé pour la mesure de l'ÉQV. Résultats : L'ÉQV avait une bonne reproductibilité inter-observateur $(\mathrm{r}=0,920 ; \mathrm{p}<0,001)$. Le score à l'ÉQV diminuait progressivement avec l'âge chez les sujets normaux, ce qui va avec une diminution de la fonction sensitive avec l'âge. L'ÉQV était significativement plus bas chez les patients atteints de SEPpar rapport aux témoins appariés pour l'âge ( $<<0,001)$. On a observé des anomalies de l'ÉQV chez des patients atteints de SEPdepuis peu de temps ( $<5$ ans) et ayant des scores bas à l'EDSS, ce qui témoigne de la présence d'anomalies sensitives précoces chez certains patients. Il existait une forte corrélation entre l'ÉQVet l'EDSS ( $\mathrm{r}=-0,509)$. L'ÉQV était corrélée à des anomalies de la sensibilité au niveau des mains $(\mathrm{r}=0,310)$, mais n'atteignait pas le seuil de significativité quant aux anomalies de la sensibilité aux pieds ou au visage. Une deuxième cohorte de patients atteints de SEP a été étudiée au moyen de l'ÉQV modifiée (stimulation unique, sans mesure au niveau du front) qui a confirmé la corrélation entre l'ÉQV modifiée et l'EDSS ainsi que l'âge. L'ÉQV modifiée peut être utile en pratique clinique vu sa rapidité d'utilisation et sa bonne corrélation à l'EDSS $(\mathrm{r}=0,578)$. Conclusions : L'ÉQV est une échelle sensitive continue, applicable chez la plupart des patients atteints de SEP, qui ne demande qu'un équipement standard au chevet du patient et qui peut éviter certains écueils dans l'évaluation sensitive de ces patients

Can. J. Neurol. Sci. 2004; 31: 490-493

Sensory abnormalities are commonly seen in patients with multiple sclerosis (MS). ${ }^{1}$ Sensory loss is common, varying from mild decreases in sensory perception to anesthesia, and showing wide variations in patterns. ${ }^{2}$ Loss of sensation can be attributed to the multifocal demyelinating lesions seen in the spinal cord and brain of patients with MS. Conduction block, temporal dispersion, and slowed conduction all may underly the physiological abnormalities. ${ }^{3}$ The most frequently noted paraesthesiae are numbness or tingling in the extremities. ${ }^{1}$
Positive phenomena are common, and may reflect mechanisms unrelated to those causing sensory loss (i.e. ephaptic transmission, abnormal response to mechanical stimulation, abnormal

From the Lehigh Valley Hospital, Allentown, Pa. 18103 USA

ReCeived February 20, 2003. AcCePtedin FinAlForm July 19, 2004. Reprint requests to: A.D. Rae-Grant, 1210 S. Cedar Crest Blvd., Allentown, Pa., 18103, USA 
sodium channel firing). ${ }^{3}$ Distal paresthesiae and sensory loss in the feet are common, probably related to the length of afferent pathways which may be interrupted at multiple levels by MS plaques in the central nervous system.

The assessment of sensory symptoms and signs is complex, and yet integral to a complete neurological evaluation. On the basis of our anecdotal observation that vibration threshold abnormalities were common in our MS population, we undertook to more formally test the use of a simple bedside measure of this aspect of sensory function.

\section{Patients And Methods}

\section{Patient Recruitment}

Patients gave informed consent and were enrolled in this study during their follow-up appointments at the MS center of the Lehigh Valley. All patients were examined by a neurologist and evaluated using the Kurtzke expanded disability status scale (EDSS). ${ }^{4}$ The patient group consisted of patients with definite $\mathrm{MS}^{5}$ with relapsing, secondary progressive, or primary progressive disease course. ${ }^{6}$ Patients were excluded if they had a history to suggest a superimposed neuropathy or other known cause of sensory loss. The control group consisted of normal volunteers or patients with other neurological diseases excluding those with sensory symptoms or peripheral neuropathies (e.g. migraine). Controls were questioned as to the presence of diabetes mellitus, sensory symptoms in hands and feet, or peripheral neuropathy and were excluded if the response was positive. Data on age, sex, presence of sensory symptoms and their character, type of MS (if applicable), and duration of MS (if applicable) were obtained.

A second group of MS patients (various types) was studied using a modified Vibration Quantitation Scale (mVQS) (see methods).

\section{Methods}

All patients were questioned about the presence of numbness and/or tingling in their face, hands, and feet. Vibration sensation was tested in all participants using a standard C-128 vibrations tuning fork (Miltex Instrument Company, Inc., Bethpage, NY, USA,11714). A maximal stimulus was obtained by striking the tuning fork against the examiners hypothenar eminence. The tuning fork was applied to the middle of the forehead, the distal interphalangeal (dip) joint of the second digit of both hands, and the distal interphalangeal joint of the great toe of both feet. Patients were asked to report the presence of vibration, and when the vibration sensation disappeared. The time that vibration persisted from initiation of vibration was measured in seconds. If there was an amputation, the score from the opposite limb was used as a substitute. The procedure was performed three times at each site, and the longest duration was used. The Vibration Quantitation Scale (VQS) was the sum of all trials and is measured in seconds (forehead + right hand + left hand + right foot + left foot). Patients in the experimental group were additionally assessed in regard to touch, pin, position, and temperature sensation as well as a timed walk, if applicable. In order to test inter-observer reproducibility, two examiners (ARG and JC) measured VQS independently in a subgroup of 25 patients. The EDSS was assessed in all MS patients at the time of their VQS measurement. The EDSS rater (ARG) and the VQS raters (NE or JC) were blinded to each other's results.

In a second cohort of MS patients, a mVQS was obtained. With these patients, a single maximal stimulus was used at each measurement site. Vibration duration after a maximal stimulus was measured in seconds in four limbs as described above, omitting a forehead measurement. The mVQS was the sum of the four scores.

\section{Statistical Analysis}

Data analysis was performed by Dr. T. Wasser (Health Studies, Lehigh Valley Hospital). For the reliability analysis for inter-observer agreement, a Pearson's correlation coefficient was used. A correlation of 0.90 or higher was considered good evidence of agreement. Categorical data were analyzed using chi-square analysis between MS patients and controls. Continuous variables were analyzed with group t-tests between MS and control groups. Analysis of variance was utilized for the substrata groups within MS (primary, secondary and relapsing). Post-hoc analyses were performed using the Scheffe procedure. Any $\mathrm{p}$-value less than $0.05(\mathrm{p}<0.05)$ were considered significant for these analysis methods.

\section{RESULTS}

All patients and control subjects were able to cooperate with VQS testing and answering questions on a brief survey. The initial study group consisted of 78 patients with definite MS (24 male, 54 female), using criteria described by McDonald et al. ${ }^{5}$ Thirty-seven patients had relapsing MS (five male/32 female); 24 had secondary progressive (12 male/12 female); and 11 had primary progressive MS (five male/six female). An MS classification was not obtained in six patients. The control group was comprised of 65 volunteers or patients with other neurological diagnoses $(n=65 ; 20$ male, 45 female). Average ages were 47.30 \pm 9.05 (Mean \pm standard deviation) for the MS group, and 49.28 \pm 16.09 for the controls $(p=0.381$ ). Members of the experimental group had a duration of MS ranging from three to 32 years (average $13.17 \pm 7.31$ years).

The overall VQS analysis yielded a mean value of 55.18 \pm $20.48 \mathrm{sec}$ for the MS group and 74.46 $\pm 13.30 \mathrm{sec}$ for the control group ( $\mathrm{p}<0.001 ; \mathrm{t}=6.514)$. The VQS was analyzed by age- group (Table 1). This showed a decrease in VQS with increasing age, as well as a consistent reduction in VQS in the patient populations. We examined the means for VQS for each MS type. Those of primary progressive and secondary progressive MS differed significantly from relapsing MS (primary $44.00 \pm 17.38$ sec, secondary $45.58 \pm 16.95 \mathrm{sec}$, relapsing $66.72 \pm 16.53 \mathrm{sec}$, $\mathrm{p}<0.01)$. Primary and secondary progressive patients did not significantly differ from each other.

The analysis of the inter-observer subgroup showed an $r$ value of 0.920 for inter-observer reproducibility $(\mathrm{N}=25)$.

The VQS was correlated with the EDSS measure in this group of patients $(\mathrm{r}=-0.509)$. Lower VQS correlated with a higher EDSS score. There was a trend towards a correlation with MS duration $(r=-0.213)$. There was a correlation between the presence of symptoms in the hands and trend towards a correlation with symptoms in the feet $(r=-0.310$ hands, $r=-0.224$ feet correlated with VQS).

The $95 \%$ lower limit for normals for VQS in this group was 48.34 seconds. Using 49 seconds as a cutoff, ROC curves yield 
Table 1: Average VQS \pm SD by Age group for MS and controls

\begin{tabular}{|c|c|c|c|c|c|}
\hline & 25-34 years & $35-44$ & $45-54$ & $55-64$ & $65-74$ \\
\hline & $\mathrm{MS} n=7 ; \mathrm{C} n=16$ & $\mathrm{MS} n=15 ; \mathrm{C} \mathrm{n}=10$ & $\mathrm{MS} n=38 ; \mathrm{C} \mathrm{n}=14$ & $\mathrm{MS} n=14 ; \mathrm{C} \mathrm{n}=10$ & $\mathrm{MS} \mathrm{n}=2 ; \mathrm{C} \mathrm{n}=15$ \\
\hline & $\mathrm{p}=0.087 ; \mathrm{t}=1.99$ & $\mathrm{p}=0.064 ; \mathrm{t}=1.95$ & $\mathrm{p}<0.0001 ; \mathrm{t}=4.46$ & $\mathrm{p}=0.002 ; \mathrm{t}=3.48$ & $\mathrm{p}=\mathrm{n} / \mathrm{a} ; \mathrm{t}=\mathrm{n} / \mathrm{a}^{*}$ \\
\hline MS & $69.6 \pm 17.8 \mathrm{~s}$ & $58.7 \pm 24.4 \mathrm{~s}$ & $52.5 \pm 19.6 \mathrm{~s}$ & $51.7 \pm 20.4 \mathrm{~s}$ & $53.5 \pm 0.7 \mathrm{~s}$ \\
\hline Control & $83.6 \pm 8.2 \mathrm{~s}$ & $74.6 \pm 9.8 \mathrm{~s}$ & $77.5 \pm 12.5 \mathrm{~s}$ & $75.4 \pm 7.8 \mathrm{~s}$ & $61.2 \pm 14.2 \mathrm{~s}$ \\
\hline
\end{tabular}

*No p-value or t-value due to small sample size in experimental group.

a sensitivity of $90 \%$, specificity of $55 \%$, positive predictive value of $36 \%$ and negative predictive value of $95 \%$.

In the second cohort of MS patients, the mVQS was measured (See Table 2). There continued to be a strong correlation with EDSS ( $r=-0.578)$ as well as weaker correlation with disease duration $(r=-0.213)$ This measurement took no longer than one minute to perform. The omission of a forehead measurement did not significantly change the correlation.

\section{DISCUSSION}

All neurologists are confronted with the task of evaluating and measuring sensation at the bedside or in the clinic. While tedious mapping of regions of sensory loss and various modalities of sensation may be useful, too often the sensory exam is limited to the presence or absence of pinprick and touch, as well as a subjective assessments of vibration and position sense in the limbs. Present neurological scales are problematic in their measurement of sensory function. For example, the MS functional composite has no subscale for sensation. ${ }^{7}$ The Scripps neurological scale ${ }^{8}$ has a sensory subscale, but lacks precision in defining the degree of impairment. In the case of the EDSS, ${ }^{4}$ sensory scoring does not affect the score if patients have sufficient ambulatory impairment to impair walking distance. In addition, on the EDSS loss of sensation in one limb is equivalent to moderate decrease in touch or pain and/or loss of proprioception for most of the body (functional system score 5). Thus there is a place for a simple bedside test of sensation that could be applied in this population, even if it does not measure every aspect of sensory dysfunction.

Few studies are available which assess sensory measures in

Table 2: Second MS cohort with modified VQS, single stimulation

\begin{tabular}{lccc}
\hline AGE & $\mathbf{N}$ & Mean $\mathbf{m V Q S}$ & $\mathbf{\pm S D}$ \\
$25-34$ yrs & 8 & $47.38 \mathrm{~s}$ & $19.82 \mathrm{~s}$ \\
$35-44$ & 10 & $41.30 \mathrm{~s}$ & $15.25 \mathrm{~s}$ \\
$45-54$ & 11 & $40.18 \mathrm{~s}$ & $13.81 \mathrm{~s}$ \\
$55-64$ & 7 & $34.29 \mathrm{~s}$ & $10.32 \mathrm{~s}$ \\
$65-74$ & 7 & $27.57 \mathrm{~s}$ & $14.11 \mathrm{~s}$ \\
Total & 43 & $38.77 \mathrm{~s}$ & $15.65 \mathrm{~s}$ \\
\hline
\end{tabular}

Modified VQS=sum of vibration duration (seconds) in 4 limbs
MS. Martina et $\mathrm{al}^{9}$ used the Rydel-Seiffer tuning fork, a $64 \mathrm{~Hz}$ tuning fork with a $0-8$ scale measurement depending on the amplitude of vibration. They showed that vibration as measured by this method gradually diminished with age, and was abnormal in most patients they studied with neuropathy. This quantitated measure has not been applied in MS, and the Rydel-Seiffer tuning fork is not widely applied in clinical neurological practice in the United States. Meh and Denislic ${ }^{10}$ used a hand held Vibrameter in a small group of MS patients and correlated these with somatosensory evoked potential (SSEP) measures. They were not able to show correlations between SSEP abnormalities in this group, but did not look at the relationship between sensory symptoms, EDSS, and changes on Vibrameter measurements. Vibrameters are not widely available for clinical use.

Merchut and Gruener ${ }^{11}$ used quantitated sensory threshold testing in 12 patients with MS, and found that 9/12 (75\%) had abnormalities of either vibratory or thermal stimulus response. They found that most of their patients (10/12) had SSEP abnormalities, but the study was limited in size.

Heijenbrok et $\mathrm{al}^{12}$ measured vibratory perception threshold (VPT) and thermal discrimination threshold (TDT) in 33 patients with clinically definite MS. The VPTmeasures were abnormal in $68 \%$ of patients, while TDT was abnormal in only $30 \%$. Paresthesiae were present in most of these patients but the authors did not correlate the presence of such symptoms with measured abnormalities. Quantitated sensory testing requires specialized equipment and operator training. ${ }^{13}$

We were able to show that a readily available, simple bedside tool (the C-128 tuning fork) provided a rapid measure of sensation when applied in the MS population. This was easy to administer, applicable to all patients with MS able to report sensation, and had a high inter-observer reproducibility. Such a simple tool is more likely to be applied in clinical practice than methods requiring specialized tools or prolonged measurements.

Symptoms of altered sensation are common in MS and may be a presenting feature. ${ }^{14}$ Sanders and Arts $^{1}$ found that 51/127 $(40 \%)$ patients had sensory symptoms as a presenting feature, and $107 / 127(84 \%)$ had persistent paresthesiae at the time of their evaluation. These authors noted a discrepancy between the presence of sensory symptoms and the presence of measurable sensory loss. This may be because of positive sensory symptoms whose mechanisms (ephaptic transmission, abnormal response to mechanical stimulation, central reorganization) may be independent of the conduction block which likely underlies measurable sensory loss. However, some of the discrepancy may lie in insensitive measures of sensation at the bedside. 
In our study, the VQS correlated well with the extent of disability (EDSS) and modestly with duration of the disease. Patients with MS showed abnormalities of VQS compared with controls. The VQS did not 'discriminate' the MS population from normals, as one would expect from a heterogenous disorder in which some patients have relatively limited physical findings. The VQS provided a numerical measure that correlated with disability as measured by the EDSS. A cut off of 49 seconds for VQS provides a sensitive measure of MS abnormalities or sensation.

Measures of VQS declined with age in both patient and control groups. This is consistent with other measures of sensory function. ${ }^{9}$ This age effect has to be taken into consideration in bedside assessment of vibration function in more elderly patients.

The VQS provides a valid, reproducible, continuous measurement that may be used to quantitate vibration in MS. The correlation with EDSS suggests that VQS might be a useful adjunct to clinical rating scales for MS in the future.

\section{REFERENCES}

1. Sanders EACM, Arts RJHM. Paraesthesiae in multiple sclerosis. J Neurol Sci 1986; 74: 297-305.

2. Paty DW. Initial Symptoms. In: Burks JS, Johnson KR. Multiple Sclerosis: Diagnosis, Medical Management, and Rehabilitation. New York: Demos Medical Publishing 2000; 75-80.

3. Waxman SG. Acquired channelopathies in nerve injury and MS. Neurology 2001; 56:1621-1627.

4. Kurtzke JF. Rating neurologic impairment in multiple sclerosis: an expanded disability status scale (EDSS). Neurology 1983; 33: $1444-1452$.
5. McDonald WI, Compston A, Edan G, et al. Recommended diagnostic criteria for multiple sclerosis: guidelines from the International Panel on the Diagnosis of Multiple Sclerosis. Ann Neurol 2001; 50(1):121-127.

6. Lublin FD, Reingold SC. Defining the clinical course of multiple sclerosis: results of an international survey. Neurology 1996; 46: 907-911.

7. Cutter GR, Baier ML, Rudick RA, et al. Development of a multiple sclerosis functional composite as a clinical trial outcome measure. Brain 1999; 122(5): 871-882.

8. Sipe JC, Knobler RL, Braheny SL, et al. A neurological rating scale (NRS) for use in multiple sclerosis. Neurology 1984; 34:13681372.

9. Martina IS, van Koningsveld R, Schmitz PI, van der Meche FG, van Doorn PA. Measuring vibration threshold with a graduated tuning fork in normal aging and in patients with polyneuropathy. European Inflammatory Neuropathy Cause and Treatment (INCAT) group. J Neurol Neurosurg Psychiatry 1998; 65(5): 743747.

10. Meh D, Denislic M. Correlation between temperature and vibration thresholds and somatosensory evoked potentials. Electromyogr Clin Neurophysiol 2000; 40:131-134.

11. Merchut MP, Gruener G. Quantitative sensory threshold testing in patients with multiple sclerosis. Electromyogr Clin Neurophysiol 1993; 33:119-124.

12. Heijenbrok MW, Anema JR, Faes TJC, et al. Quantitative measurement of vibratory sense and temperature sense in patients with multiple sclerosis. Electromyogr Clin Neurophysiol 1992; 32: 385-388.

13. Goldberg JM, Lindblom U. Standardized method of determining vibratory perception thresholds for diagnosis and screening in neurological investigation. J Neurol Neurosurg Psychiatry 1979; 42:793-803.

14. Rae-Grant, AD, Eckert NJ, Bartz S, Reed JF. Sensory symptoms of multiple sclerosis: a hidden reservoir of morbidity. Multiple Sclerosis 1999; 5:179-183. 